\title{
O ISEB E A CONSTRUÇÃO DE BRASÍLIA: correspondências míticas
}

\author{
Márcio de Oliveira*
}

Resumo: Este artigo trata da relação entre o Instituto Superior de Estudos Brasileiros (ISEB), a construção da atual capital do Brasil, a cidade de Brasília e as ideologias nacionalistas. $\mathrm{O}$ estudo analisa com brevidade a produção bibliográfica dos professores Alberto Guerreiro Ramos e Hélio Jaguaribe, e, com maior profundidade, a produção de Roland Corbisiser (diretor do Instituto entre 1955 e 1959). Afirma-se que entre o ISEB e o nacionalismo desenvolvimentista kubitschekiano havia muitos pontos em comum. Mas teria havido mais do que uma concordância de forma e de conteúdo entre as idéias defendidas pelo governo JK e aquelas defendidas por intelectuais do ISEB. Examinando a história do Instituto, as circunstâncias sociopolíticas predominantes durante o mandato de JK (1956-61) e as teses empregadas para defender a transferência da capital, nota-se o apoio de muitos intelectuais à construção da capital. Não obstante, conclui-se que não há relação de causalidade ou determinância entre as principais teses do ISEB e a política do governo JK em relação a Brasília. Correspondências e cumplicidades míticas explicam melhor a realidade que fez unir esses atores em torno do tema geral da construção da nação.

Palavras-chave: ISEB, Brasília, nacional-desenvolvimentismo.

Doutor em Sociologia pela Universidade de Paris V; coordenador do Programa de Pós-graduação em Sociologia da Universidade Federal do Paraná (UFPR). E-mail: marciodeoliveira@ufpr.br

Este trabalho tem por origem a minha tese de doutorado em Sociologia: Étude sur l'imaginaire brésilien: le mythe de la nation et la ville de Brasília, defendida na Universidade de Paris $\mathrm{V}$.

Artigo recebido em 27 set 2005; aprovado em 22 dez 2005. 
O governo do presidente Juscelino Kubitschek de Oliveira (1956-1961) procurou apoiar seu projeto de transferência da capital do Rio de Janeiro para o planalto goiano em opiniões e análises dos mais variados matizes, desde as tentativas de interiorização e resgate do "Brasil esquecido" até as propostas de modernização da infra-estrutura (produção de energia e indústrias de bens de capital) do país e de industrialização do setor produtivo de bens de consumo (Moreira, 1998; Oliveira, 2005). Grosso modo, estas análises de caráter político e/ou científico, surgidas desde o final dos anos 1940 e reaproveitadas durante o período de construção da cidade (1956-1960), apresentavam como tema de fundo a nação ou ainda a "questão nacional", mantendo estreitos (mas nem sempre voluntários) laços com as ideologias nacional-desenvolvimentistas da época e, em particular, com as análises intelectuais oriundas do Instituto Superior de Estudos Brasileiros (ISEB).

Os temas favoritos do governo JK, com exceção de Brasília, já eram debatidos pelos intelectuais que fundaram o ISEB desde antes de sua criação. ${ }^{1} \mathrm{JK}$ conheceu alguns deles durante sua campanha à presidência. Sodré (1978) afirma que alguns intelectuais teriam visto na candidatura de JK ora uma plataforma política semelhante aos seus ideais, ora mesmo uma possibilidade de trabalhar e assessorar diretamente o possível futuro presidente. Assim, passaram a apoiar a candidatura de JK e chegaram mesmo a sustentar sua posse ocorrida sob estado de sítio. Não é de se admirar, portanto, que o governo tenha se aproximado do ISEB. Mas não deixa de ser relevante o fato de que o principal momento do ISEB se deu justamente durante o governo JK. Isso se deve em parte graças aos recursos públicos destinados ao Instituto via Ministério da Educação e Cultura. Mas a principal razão talvez seja o impulso político ocorrido quando o ex-presidente incumbiu ao Instituto a tarefa de dar sustentação ideológica à política desenvolvimentista de seu governo (Sodré, 1977). O apoio público de JK acabou por reforçar tanto o Instituto quanto o nacional-desenvolvimentismo.

Havia, é claro, uma certa concordância entre os temas isebianos e o sentido geral do programa de governo de JK. Contudo, 
isso não se estendeu a todos os projetos governamentais. Em relação ao projeto de transferência da capital e de construção de Brasília, houve ora apoio explícito, ora omissão. JK anunciou repetidamente a construção da nova capital como sendo "um ato de fundação do novo Brasil", revelando assim uma vontade de dividir a história brasileira - e o próprio destino da nação - em "antes e depois de Brasília". Mas, o que pensaram os isebianos dos grandes projetos kubitschekianos? A capital precisava realmente ser transferida para o planalto goiano? A anunciada nova capital significaria realmente a "refundação do Brasil"?

A transferência da capital foi abertamente apoiada por intelectuais ligados ao Instituto e, assim, cabe investigar as razões desse fato. Concordância de visões? Apoio episódico ou incondicional? Em resumo, como compreender a relação que pouco a pouco se estabeleceu entre os intelectuais ligados ao ISEB e o projeto governamental de transferência da capital?

Para responder a estas questões, este estudo parte do exame tanto da história do ISEB quanto da produção bibliográfica de seus membros, dando especial ênfase à de Roland Corbisier (diretor do Instituto entre 1956 e 1959) e, em menor escala, à de Alberto Guerreiro Ramos e de Hélio Jaguaribe. À luz desses estudos, examinamos suas obras e os possíveis laços existentes em relação aos principais argumentos apresentados pelo governo JK para transferir a capital do Brasil.

\section{As origens do ISEB e o governo JK}

Fazer do Brasil uma nação moderna, independente e desenvolvida é um dos temas mais recorrentes na história do pensamento social brasileiro, seguramente desde meados do século XIX (Oliveira, 1994). Eis porque o programa desenvolvimentista anunciado por JK - materializado em seu famoso "Programa de Metas" - reverberou (seja em forma de eco, seja em forma de críticas) também nessa geração de intelectuais que, nos anos 
1950, reunia nomes como os de Alberto Guerreiro Ramos, Hélio Jaguaribe, Roland Corbisier, Costa Pinto, Roberto Campos, Lucas Lopes, Cândido Mendes, Pedro Calmon, Ignácio Rangel, Álvaro Vieira Pinto, Gilberto Freyre, Sérgio Buarque de Holanda, Nélson Werneck Sodré, entre outros. Embora a questão nacional não fosse uma novidade em si, aqueles anos 1950 apontavam para uma nova perspectiva na maneira de abordá-la. Se, no começo do século XX, o Estado era uma entidade sem perfil nacional e pouco operante administrativamente, a partir dos anos 1940, nenhum intelectual menospreza seu papel e influência na vida econômica e social do país. Mais: desde o final do Estado Novo, todas as questões centrais que dizem respeito à nação convergem para a estrutura de um Estado já bem mais nacionalizado e organizado burocraticamente. Não obstante, as análises intelectuais e políticas do período apontavam para uma nação ainda sem perfil social e econômico consolidado. Nessas condições, era pouco provável que os diversos atores sociais lograssem construir um projeto nacional. Este caberia ao Estado. Com a expansão na oferta de bens e serviços e na taxa de investimentos, segundos estudos do BNDE, ${ }^{2}$ o Estado lentamente se preparava para a tarefa que se apresentava.

Segundo Cardoso (1978, p. 386), "em toda a década de 40 e até a metade da década de 50, o Brasil apresenta um crescimento econômico considerável". Acreditava-se porém que as condições que permitiram aquele crescimento não se repetiriam, sobretudo devido à depreciação das relações de intercâmbio. Esta tendência já havia sido indicada por Prebisch (1949) e seria confirmada em estudos da CEPAL (Moraes, 1985). A questão da dependência, entendida tanto do ponto de vista das relações econômicas quanto das relações políticas travadas entre países "subdesenvolvidos" e países "desenvolvidos", era apontada como o nó estrutural a ser vencido. Além disso, o quadro econômico do Brasil revelava um país rural ostentando uma pauta de exportações essencialmente agrícola na qual, para o ano de 1955, 60\% eram provenientes do café. Faro e Silva (2002, p. 67-105), diagnosticando a realidade socioeconômica do Brasil de então, apresentam um quadro bastante minucioso do qual podemos ressaltar: 
1) $58,82 \%$ da população economicamente ativa no setor primário;

2) baixa produtividade agrícola;

3) $60 \%$ das exportações provenientes da venda de café;

4) siderurgia e indústria automobilística emergente;

5) indústria nacional de cimento abastecendo $90 \%$ do consumo doméstico;

6) produção nacional de energia elétrica abastecendo $25 \%$ das necessidades domésticas;

7) $3.000 \mathrm{~km}$ de estradas pavimentadas;

8) 13,5 telefones instalados por 1.000 habitantes.

Em termos de política macroeconômica, o Brasil oscilava entre o desenvolvimentismo e o monetarismo. Segundo Lafer (2002, p. 13), o governo JK surge nesse cenário propondo, já em sua primeira Mensagem Presidencial enviada ao Congresso Nacional no início de 1956, a transformação da máquina político-administrativa nacional através de um Programa de Metas, cuja função seria a de um "fulcro irradiador" e cuja tônica seria o desenvolvimento. Era o início das políticas nacionais de desenvolvimento e foi este também, coincidentemente, o momento de criação do ISEB.

A origem do ISEB remonta ao pequeno grupo de intelectuais - dito Grupo de Itatiaia ${ }^{3}$ - que havia criado, em 1953, o Instituto Brasileiro de Economia, Sociologia e Política (IBESP). A atuação do IBESP consistia em ministrar cursos sobre realidade brasileira no auditório do Ministério da Educação e Cultura. O IBESP contava com o apoio de Anísio Teixeira e tinha como sede o escritório de advocacia de Hélio Jaguaribe e Reinaldo Reis, localizado na rua do Ouvidor, cidade do Rio de Janeiro.

Em 1955, o mesmo grupo de intelectuais do IBESP, a partir do convênio firmado com a Coordenação de Aperfeiçoamento 
de Pessoal de Nível Superior (CAPES) ${ }^{4}$ levaria ao Ministro da Educação e Cultura, Antônio Balbino, a idéia de criação de um centro de estudos, tendo por modelo o francês Collège de France e o latino-americano Colégio de México. O ISEB foi finalmente criado em 1955, por decreto, pelo ex-presidente Café Filho e funcionou até 13 de abril de 1964, pouco após a deposição do então presidente João Goulart, quando foi fechado. Embora criado ainda em 1955, a sede do Instituto só seria inaugurada, pelo próprio JK, em 1956.

$O$ projeto do ISEB resgatava àquele afirmado pelo IBESP desde o primeiro número dos "Cadernos do Nosso Tempo", qual seja, o de formular uma ideologia capaz de dar suporte teórico para a elaboração de uma "política nacional de desenvolvimento". O objetivo do ISEB era o de assessorar o governo em todas as "tarefas e matérias que o moderno Estado capitalista é hoje incumbido de realizar" (Toledo, 1978, p. 184). A criação do Instituto deu vazão a uma forma política de equacionar os problemas nacionais, acabando por distanciá-lo dos modelos do Collège de France e do Colégio de México, que haviam sido suas fontes de inspiração. Agora, tratava-se de forjar, resgatando a temática da ideologia já presente no IBESP, um pensamento brasileiro capaz de propor soluções às questões nacionais de desenvolvimento. Seu "regulamento geral" foi bastante explícito nesse sentido:

O Instituto Superior de Estudos Brasileiros (ISEB) [...] é um centro permanente de altos estudos políticos e sociais de nível pós-universitário que tem por finalidade o estudo, o ensino e a divulgação das ciências sociais notadamente da Sociologia, da História, da Economia e da Política, especialmente para o fim de aplicar as categorias e os dados dessas ciências à análise e à compreensão crítica da realidade brasileira visando à elaboração de instrumentos teóricos que permitam o incentivo e a promoção do desenvolvimento nacional (Toledo, 1978, p. 32).

Ligado diretamente a um ministério e recrutando seus alunos nas lides da administração federal, todos os estudos estariam direta ou indiretamente vinculados à estrutura do Estado. Estudos, salientese, "aplicados" porque deveriam "promover o desenvolvimento". 
De fato, o "desenvolvimento" foi o grande tema abordado por quase todos os intelectuais ligados ao ISEB. O grupo de intelectuais presente no Instituto desde sua fundação, o dito "grupo histórico", procurou, desde seus primeiros trabalhos, elaborar pesquisas e reflexões teóricas sobre a questão do desenvolvimento, direcionando-as à formulação de um nacional-desenvolvimentismo dito moderado.

Numa estratégia de consolidação de seu nome para a corrida presidencial de 1955, o então governador de Minas Gerais, JK, ainda em 1954, teria sido apresentado a estes intelectuais. JK, já eleito, trabalhou para transformar o Instituto em um centro destinado a produzir uma ideologia que justificasse seu "programa de metas", garantindo apoio de muitos deles ao governo e contribuindo para a construção da discutível imagem de fábrica de ideologia ${ }^{5}$ que lhe seria colada (Toledo, 1978).

A aproximação de JK ao ISEB não fora gratuita e menos ainda fortuita. Além do tema nacional comum, a ligação de JK com intelectuais, em especial escritores, surgira durante o período de seu governo em Minas Gerais. No seu mandato presidencial, os intelectuais continuariam tendo grande espaço em seu governo e dentre seus assessores mais próximos, o número de escritores foi importante. Entre eles, contavam-se: Afonso Ávila, Alphonsus de Guimarães Filho, Álvaro Lins, Augusto Frederico Schmidt, Autran Dourado, Cristiano Martins, Cyro dos Anjos, Fábio Lucas, Francisco de Assis Barbosa e Eduardo Portela. Werneck (2001, p. 156) afirma que JK desejou dar "brilho verbal" ao seu governo, freando, no mesmo movimento, a tendência oposicionista dos intelectuais.

Os homens acima, escritores, contistas ou poetas, podem, contudo, ser relativamente diferenciados dos intelectuais da geração isebiana. Eram antes homens bem nascidos, com ligações nas elites, inteligentes, formados ou não e, sem exceção, bons redatores. O poder deles necessitava tanto para fazer andar a máquina administrativa e burocrática do Estado quanto para manter alianças políticas. Miceli (1981) se refere a esta geração de intelectuais (1920-45) como originários das camadas oligárquicas (e de suas extensões, 
os "parentes pobres") tão comuns nos anos 1920 e 1930. Pouco a pouco, essa geração fora se modernizando, se profissionalizando à medida em que se modificava o mercado de trabalho intelectual. Talvez se possa dizer que sua vocação para ocupar cargos no poder público era antes uma estratégia "natural" de sobrevivência do que uma prática política conscientemente arquitetada. Diferentes daquela foram os homens da geração de 1945, formados sob a bandeira do nacionalismo. Pécaut (1990) se refere a estes como uma geração engajada. À diferença do grupo de escritores, contavamse agora cientistas políticos, economistas, sociólogos e juristas. Esta formação científica não poupou aos intelectuais isebianos uma certa desconfiança entre os grupos de cientistas sociais ligados à Universidade do Brasil (atual Universidade Federal do Rio de Janeiro) e mesmo à Universidade de São Paulo, que os julgavam mal preparados para analisar e formular soluções para o Brasil. Não obstante as críticas e embora em sua maioria fossem oriundos dos estratos mais elevados da sociedade, procuraram, de forma organizada e consciente, analisar e, a partir de suas opções teóricas e ideológicas, interferir politicamente nos destinos do país. Em traços gerais, esta é a geração responsável pelo ISEB.

Quando de sua criação, os responsáveis pelas cadeiras do Instituto (e, assim, pelos conteúdos dos cursos) eram: Hélio Jaguaribe (Ciência Política), Álvaro Vieira Pinto (Filosofia), Ewaldo Correira (Economia), Alberto Guerreiro Ramos (Sociologia), Cândido Mendes (História) e Nélson Werneck Sodré (História do Brasil). ${ }^{6}$ Os cursos eram ofertados com total autonomia pelos docentes que, inclusive, não freqüentavam as aulas dos colegas.

O Instituto funcionou, nos seus dois primeiros anos, 1956 e 1957, como uma instituição de ensino e pesquisa, dentro do formato previsto pelo Ministério da Educação e Cultura. Mas, em 1958, ocorre uma crise. Sodré (1978, p. 27-53) afirma que a crise foi resultado de um processo que, desde inícios de 1956, vinha dividindo os intelectuais do Instituto. O "desenvolvimentismo" kubitschekiano fora definido como uma aceleração do crescimento econômico, enquanto que aquele defendido por alguns intelectuais 
isebianos deveria apresentar uma dimensão nacionalista explícita, o que implicaria uma mudança na estrutura econômica do país. Somase a isso uma "campanha" em veículos da grande imprensa carioca na qual, lentamente, os professores do Instituto foram chamados ora de comunistas, ora de entreguistas, ora de ambos. A crise tivera como estopim a publicação do livro de Hélio Jaguaribe, Nacionalismo na atualidade brasileira, cujas afirmações sobre a exploração do petróleo e sobre as possibilidades de desenvolvimento associado a capitais externos colocaram em posições opostas algumas das figuras mais importantes do Instituto. Jaguaribe (2004, p. 1) afirma, em recente entrevista, que a crise tivera como estopim o fato de Guerreiro Ramos "ter sido acometido da falsa impressão de que o Brasil se encaminhava para uma grande revolução social no governo Juscelino". Sodré afirma que a posição de Guerreiro Ramos fora ambígua e sectária, culminando num racha decisivo que levaria tanto a seu próprio afastamento quanto ao de Hélio Jaguaribe, ocorrido pouco tempo depois. Com a saída destas duas importantes figuras, teria havido, a partir de 1959, uma lenta radicalização nas posições dos intelectuais remanescentes ${ }^{7}$ no sentido da elaboração de uma verdadeira "ideologia nacional" que, embora também pautada no desenvolvimentismo, estivesse sob o comando das camadas populares ou do operariado. Contudo, entre fins de 1958 e fins de 1960, embora caminhando para posições ideológicas mais radicais - fato que, contudo, só se tornaria mais evidente a partir de 1961, durante do governo Jânio Quadros - o Instituto se manteve próximo das propostas desenvolvimentistas defendidas pelo governo JK.

Para Toledo (1978; 1986) e Franco (1978), os intelectuais do ISEB atuaram como ideólogos. Como um todo, o Instituto produziu uma "ciência" que se transmutou em "ideologia". Agiu assim como uma "fábrica de ideologia", um "aparelho ideológico de Estado" ou ainda como a "própria consciência burguesa" da época. Esta explicação encontra, é claro, numerosos argumentos tanto no trabalho dos professores responsáveis pelas cadeiras quanto na própria ata de fundação do Instituto. Esta explicação encontrou guarida ainda em outros trabalhos. Mota (1985 [1977]) afirma que se tratava de uma 
geração em que "ingressaram acadêmicos e metamorfosearam-se em políticos".

Outros trabalhos, contudo, apresentam a produção dos intelectuais do ISEB de uma maneira mais contextualizada, nuançando suas diversas posições teórico-ideológicas e seus diversos períodos e exprimindo aqui e ali os diversos matizes político-ideológicos da época. Lamounier (1978) afirma que os intelectuais isebianos não lograram produzir uma teoria política nem mesmo uma ideologia propriamente dita, indicando assim um certo espontaneísmo e voluntarismo político. Schwartzman (1981, p. 3) definiu estes intelectuais menos pelas posições polêmicas e políticas que os animavam e mais pelo sentimento que os unia: "a preocupação com o subdesenvolvimento, a busca de uma posição internacional de não alinhamento e de "terceira força", um nacionalismo em relação aos recursos naturais do país, uma racionalização maior da gestão pública, maior participação de setores populares na vida política...". A explicação de Schwartzman (1981) retoma assim o argumento inicial: é a preocupação teórica e política em torno do tema do desenvolvimento, trabalhada desde os tempos do IBESP, aquela que mais define o Instituto. Enfim, Ortiz (1985) afirma que o Instituto não seria nem mero apêndice do governo, nem "fábrica de ideologia", mas, sim, composto por um grupo de intelectuais, heterogêneos por formação e por ideologia, que teria produzido, em sintonia com a época, diversas análises (ou ideologias) sobre a realidade nacional.

Muito ainda se pode falar a respeito da "ideologia" produzida pelos diversos acadêmicos ligados ao Instituto. Contudo, parece forçado hoje reuni-los em apenas um único grupo, em apenas uma única posição ideológica ou mesmo em resumir sua atuação ao fabrico de uma única ideologia nacional-desenvolvimentista. Talvez seja melhor falar em "ideologias". Essas (eis a hipótese) assumem novo contorno quando confrontadas ao sentimento de inexistência de nação e da necessidade de uma política de desenvolvimento (como forma de construí-la) que assaltou toda essa geração de intelectuais. De fato, 
a oposição nação/anti-nação é talvez aquela que melhor signifique o ISEB, em certa medida porque ela permitia (ainda permite?) resgatar o nível de (des)nacionalização ${ }^{8}$ do desenvolvimento brasileiro. A hipótese é que este imbricamento entre sentimento de inexistência nacional e de desenvolvimento materializou-se com uma força não imaginada no projeto governamental de mudança da capital. A construção de Brasília - devido tanto a seu caráter pedagógico de esclarecimento da (ir)realidade do Brasil quanto devido às dimensões nacionais e de potencialidades de desenvolvimento pouco a pouco vislumbradas - conferiu justa e didática imagem ao variado conjunto de pressupostos teórico-ideológicos lentamente elaborados pelos intelectuais ligados ao Instituto.

\section{O ISEB, o governo JK e a construção de Brasília}

Para ilustrar a relação do Instituto com o governo JK e com o projeto de Brasília, tomemos o caso de Roland Cavalcanti de Albuquerque Corbisier ou simplesmente Roland Corbisier (19142005). ${ }^{9}$ Paulista de nascimento, filósofo e diretor do Instituto entre 1955 e 1959, Corbisier publica, nesse mesmo período, três livros: Responsabilidade das elites (1956); Formação e problema da cultura brasileira (1958); Brasília e o desenvolvimento nacional (1960). Os dois últimos livros foram frutos de conferências realizadas pelo autor em 1955 e 1956 e em março de 1960, respectivamente. As duas primeiras aconteceram no auditório do Ministério da Educação e Cultura, durante os cursos de 'Introdução aos Problemas do Brasil' e 'Filosofia do Brasil' promovidos pelo ISEB e a terceira aconteceu no mesmo auditório no dia 31 de março do ano de 1960, no quadro de um seminário, também promovido pelo ISEB, sobre a nova capital. Assim, não nasceram como livro. A última, inclusive, foi a única conferência daquele seminário publicada pelo Instituto. ${ }^{10}$

Participando ativamente da vida política, escrevendo e apoiando publicamente o programa de governo de JK, o exemplo de Corbisier é bastante ilustrativo do papel que as questões do desenvolvimento e do nacionalismo, em sua dimensão ideológica, 
ocupavam no seio do Instituto. Mas pode-se também ver na cronologia e no significado dos livros publicados um outro sentido, mais perene. A hipótese básica é que a obra de Corbisier aproximase do tema da construção de Brasília inspirada pelo mesmo desejo de construir a nação presente no processo que levou o governo JK a esposar tarefa tão espinhosa. Esse desejo teria como lastro uma análise aparentemente inquestionável para a época: não havia nação brasileira. Urgia construí-la. Como desenvolvemos alhures (Oliveira, 1997; 2005), JK, durante todo o período da construção de Brasília, insistiu sobre o caráter redentor da obra. Em inúmeras oportunidades e para os mais diversos públicos, Brasília foi sempre apresentada como algo maior que uma cidade. Tratava-se de uma capital - e não apenas mais uma capital - mas sim aquela destinada a redirecionar o futuro da nação, a unificar internamente o país, a trazer à realidade as vastas potencialidades sempre alardeadas. $\mathrm{O}$ otimismo que tomou conta do país na "era JK" anunciava ao largo um outro país, bem diferente daquele em que se vivia.

O simbolismo nacional em torno de Brasília não se limitou apenas à própria transferência da capital. Ao contrário, alcançou de fato diversas dimensões da vida nacional. Lembremos, por exemplo, do sentimento da criação de uma modernidade verdadeiramente nacional representada pelos projetos urbanístico e arquitetônico da nova cidade. O "plano piloto" sugeria também, em sua expressão social, o surgimento de uma nova sociedade, com base em relações sociais menos desiguais. Além disso, como gigantesca obra de construção civil, inclusive graças às inúmeras obras de infraestrutura rodoviária e ferroviária que lhe dariam suporte, Brasília representava o resgate e o desenvolvimento dos "sertões" e, desde o início da edificação, já revelava efeitos sociais e econômicos em termos de crescimento e desenvolvimento.

Todas essas dimensões não apenas apontavam para tão desejada construção da nação, mas também confirmavam a tese de sua inexistência. O desejo de construir a nação foi ainda muito bem expressado pelas imagens de vazio, de começo, de incivilização do interior etc. trazidas pelos primeiros relatos e constantemente 
reforçadas pelo governo $\mathrm{JK}$, tanto em expressões tais como 'nova era de progresso", "novo Brasil que se anuncia", entre outras, quanto nos filmes e fotografias produzidas de forma organizada pela publicidade governamental. Trazidas à tona naquele contexto, as imagens do período da construção começaram a adquirir um sentido simbólico explícito. Mas o mais importante era que estas imagens pareciam associar-se menos às estruturas da lógica científica que às estruturas das narrativas míticas. Dito de outra forma, o desejo de construir o Brasil, de fazer do país uma verdadeira nação etc. surgia paradoxalmente tanto nos discursos governamentais quanto nas análises intelectuais como guias para a reflexão e para ação. Em resumo, essas imagens pareciam ser substratos culturais permanentes funcionando como um mito "modulador" da história brasileira, ou seja, como uma estrutura que sustenta simbolicamente determinadas formas de agir e de pensar.

O objeto da aproximação de Corbisier à temática de fundo do governo JK - a construção do Brasil - ultrapassa, portanto, as afinidades intelectuais e/ou político-ideológicas. Como pretendemos demonstrar a seguir, também ele teria sido influenciado por este "mito modulador"," acreditando assim que a melhor maneira de construir a nação era através da mudança da capital para o interior do Brasil.

Para fins de análise, tomemos, inicialmente, as duas conferências realizadas pelo autor. Em $A$ formação e o problema da cultura brasileira, a tese desenvolvida é: durante o período colonial, a sociedade brasileira não se constituiu porque inexistia uma estrutura econômico-nacional autêntica. Por conseguinte, a cultura e a ideologia que essa sociedade poderia criar eram igualmente inautênticas. A partir dessa tese, o livro afirma que, no primeiro período (pós-independência), o país continuava a ser dependente economicamente da Inglaterra e culturalmente da França. Esta dupla dependência não teria permitido que o país conseguisse se desenvolver apesar do crescimento quantitativo e de uma certa mudança na estrutura produtiva. A imagem de uma nação inacabada 
é tão forte quanto o fato da inexistência de um sentido histórico a ser resgatado pelos contemporâneos. O país não poderia reportar-se à sua história colonial e dependente para construir seu projeto de nação. Apenas o presente e o futuro eram solução possível. Mas como? Graças à elaboração de um projeto de transformação, de uma ideologia fundada sobre a realidade e voltada para o futuro:

[...] a transformação racional de nossa circunstância exige o seu prévio conhecimento, conhecimento esse que, por sua vez, só se torna possível em conseqüência desse projeto anterior de transformação (Corbisier, 1958, p. 86).

A transformação racional não poderia se fazer sem um conhecimento anterior da realidade. Este conhecimento seria fruto de um projeto de transformação. Temos aqui uma inversão do raciocínio lógico porque é o conhecimento da realidade que, em princípio, permite elaborar o projeto de transformação e não o contrário! Para o autor, contudo, os dados empíricos e a realidade deveriam se submeter aos projetos de transformação.

A transformação sendo considerada necessária, como não aceitar os pressupostos da ideologia nacional-desenvolvimentista exemplarmente divulgados através das imagens da cidade que se construía do "nada"? Deste momento em diante, pouco a pouco, mas firmemente, o autor apresenta, em sua obra seguinte - Brasília e o desenvolvimento nacional - os argumentos que vão fundamentar seu apoio ao governo JK. O projeto de transformação nacional, reclamado por Corbisier em tantas passagens d'A Formação... encontra no projeto de transferência da capital mais que uma expressão palpável. Encontra a resposta, a concreta possibilidade de retirar o país do marasmo, do arcaísmo de suas tradições coloniais. O título da obra - Brasília e o desenvolvimento nacional ${ }^{12}$ - é mais que uma análise. Assemelha-se a uma convocação imperiosa em direção ao futuro do país. Neste livro, logo de início, o autor retoma os mesmos argumentos já desenvolvidos n'A Formação.... o Brasil não era uma nação. 
[...] termos proclamado nossa independência há quase um século e meio, não quer dizer que tenhamos por essa razão, e ao mesmo tempo, conquistado também a nossa independência econômica e cultural. Soberanos politicamente, ao menos na forma legal, continuamos a ser colônia econômica da Inglaterra e colônia cultural da França. E o nosso crescimento econômico, que se processou até o início da industrialização, não alterou a fisionomia do País, a estrutura do seu aparelho de produção, de suas classes sociais, de suas instituições políticas e administrativas, nem tampouco o estilo de sua vida cultural. A unidade nacional se reduzia à unidade do território, da língua e da organização política. Do Império centralizador à República Federativa, não se afrouxaram os laços dessa unidade, embora o País, pela própria extensão continental, pela escassez ou inexistência de meios de comunicação e de transporte, pelo centrifuguismo de sua economia dependente, carecesse de mercado interno e, portanto, de integração econômica e social. A rigor, nunca houve sociedade nem povo brasileiro (Corbisier, 1958, p. 161162).

A independência política de nada nos teria servido. A história do Brasil é apresentada como uma longa caminhada de dependência em dependência. Do plano econômico ao cultural, dois países: Inglaterra e França. O final da passagem é taxativo: nem sociedade, nem povo. Estava resumido o Brasil. Preparava-se nestes termos o terreno para a intervenção, para o conjunto de soluções que tornariam o Brasil uma nação independente. Este conjunto não poderia esperar o natural desenvolvimento das forças sociais e econômicas. O autor propõe a idéia, ou melhor, um conjunto de idéias. O tema-base deste conjunto de idéias era a integração. ${ }^{13}$ Contudo, inconsciente de seu lastro mítico, essa imagem era apresentada como a condição para a existência de um mercado interno e para a industrialização, temas presentes em análises que vão da CEPAL, passando por Celso Furtado até o Partido Comunista do Brasil. O fundamento dessa análise é, portanto, político e ideológico, mas seu lastro é mítico porque implicitamente admitia a inexistência da nação. Assim, o autor poderia afirmar que o desejo de construir a nação já se encontrava em germe à espera de tarefas que a trouxessem à vida: 
Essa tarefa, porém, de desenvolvimento, de integração nacional, de construção da Nação brasileira, essa tarefa, embora seja de conteúdo econômico e social, é, fundamentalmente, política e ideológica. Não são as forças de mercado, entregues à sua espontaneidade, ao seu livre jogo, que nos permitirão corrigir os desequilíbrios internacionais e os desequilíbrios internos, promovendo, no prazo que nos interessa, o desenvolvimento harmonioso e equilibrado do País. (Corbisier, 1958, p. 167).

Uma intervenção faria o país se desenvolver. A tarefa era a da construção da nação. Uma tarefa ideológica, como bem assinala o autor, mas também política. E qual seria esta política? Qual ideologia seria capaz de reorientar o desenvolvimento nacional e de mudar estruturas seculares? A resposta estava em andamento. Era o projeto de transferência da capital e a construção de Brasília: ${ }^{14}$

Ao edificar a cidade, não só o homem se liberta da servidão à natureza e dos misteres elementares da sobrevivência, como fabrica a moldura, o contexto no qual passa a realizar sua existência. [...]. Todas as grandes culturas e civilizações que conhecemos, encontram, por assim dizer, seu arremate e seu coroamento na construção da Metrópole, da grande capital. (Corbisier, 1960, p. 173).

O projeto de transferência tem uma importância tão grande que chega a ser comparado com o papel que as próprias cidades deveriam ter no contexto civilizatório. Corbisier (1960, p. 173) continua:

Para atender às exigências do desenvolvimento, da integração econômica e cultural do País, tornava-se imperativo e urgente interiorizar a Metrópole, transferindo-a para o coração de nosso território.

Integração versus dispersão; união versus desagregação. A solução era a interiorização da metrópole. Era Brasília no coração do Brasil. As estradas de integração - sobretudo a Belém-Brasília e a Brasília-Acre - são invocadas para confirmar que um novo país surgia. Corbisier conclui:

$\mathrm{Na}$ hora matutina em que assistimos ao nascimento na Nação, em que energias poderosas e indecisas despendem-se da crisálida e 
tomam forma diante de nós, nessa hora inaugural em que se deseja a fisionomia do novo País, livre e soberano, celebremos o privilégio de sermos os contemporâneos da epopéia de Brasília, a flor do deserto, a Capital do futuro e da esperança. (Corbisier, 1960, p. 179).

Saliente-se ainda o paralelo entre os termos - novo País, livre e soberano - empregados por Corbisier àqueles empregados por outros intelectuais e por outros membros do governo JK. Comunhão de idéias, ideologia política comum ou correspondências míticas? Ausência de sociedade, necessidade de uma ideologia que construísse a nação, necessidade de desenvolvimento, ocupação do território são alguns dos temas que instigaram os intelectuais brasileiros durante a construção de Brasília. Se, em Corbisier, havia uma nítida recuperação do mote mítico da inexistência da nação, que dizer de outros isebianos?

Guerreiro Ramos apresenta uma análise bastante semelhante àquela de Corbisier, como se pode ver já no prefácio de seu livro:

Demos a este livro o título de O problema nacional do Brasil com plena consciência de que ele vai situar-se na tradição da sociologia militante no País, que vem desde o Visconde do Uruguai, Paulino José Soares de Souza, até Oliveira Vianna, passando por Sílvio Romero, Euclides da Cunha e Alberto Torres. Este último autor publicou, em 1914, O problema nacional brasileiro. O presente livro, como o de Alberto Torres, é uma tentativa de utilizar a ciência social como instrumento de organização da sociedade brasileira (Ramos, 1960, p. 13-14).

Também em Guerreiro Ramos, o conhecimento deveria ser aplicado, deveria servir de "instrumento de organização...". ${ }^{15}$ Mas por que se deveria organizar a sociedade? A resposta a esta questão, dentro do desenrolar do texto, não tarda muito. Analisando os grandes momentos da história do Brasil, desde a Independência até os anos 1920, na mesma perspectiva histórico-metodológica de Corbisier, Guerreiro Ramos (1960, p. 21-22) afirma que, "dominado por fazendeiros" em seu período colonial, o "Brasil foi um país sem povo [...]. País sem mercado interno, sem sistema nacional de 
transportes e comunicações". A má formação da sociedade brasileira era conseqüência, uma vez mais, do período colonial. Trata-se de uma explicação que se tornaria unanimidade nos manuais de história dos ensinos fundamental e médio: "Maldita colonização portuguesa", repleta de bandidos, aventureiros etc. - repetir-se-ia. Frente a um tal "pecado original", a saída ou a solução não poderia ser senão uma "revolução nacional" recheada de industrialização, de progresso, enfim, de "nacionalização" conclui o autor às últimas páginas de seu livro:

Nas últimas décadas é cada vez mais evidente que o Brasil está realizando sua revolução nacional, isto é, está adquirindo os requisitos materiais de verdadeira nação (Ramos, 1960, p. 245.)

"Nas últimas décadas", conforme descreve o autor, o país se industrializa, progride. Estava "adquirindo os requisitos materiais de verdadeira nação". Devia-se concluir, contudo, que o país ainda não realizara sua revolução nacional, ainda não revolucionara suas condições materiais de produção. Conseqüentemente, ainda que Guerreiro Ramos não tenha apoiado abertamente o projeto de transferência da capital, o tom de sua análise é próximo daqueles de Corbisier e de JK.

O mote da inexistência é o ponto de partida da narrativa mítica na trajetória do pensamento social brasileiro. $\mathrm{O}$ ponto de chegada variaria de autor para autor. Em $O$ nacionalismo na atualidade brasileira, Hélio Jaguaribe defende a tese segundo a qual o "nacionalismo" era a melhor forma de unir e desenvolver o país. Esta tese foi o resultado de um trabalho iniciado em 1952, com a publicação de seu ensaio A Filosofia no Brasil (republicado pelo ISEB em 1957), onde demonstrava a ausência de uma verdadeira filosofia brasileira porque nossos intelectuais estavam demasiado impregnados das "filosofias estrangeiras". 


\section{Conclusão}

Pode-se afirmar que a inexistência da nação era o pivô em torno do qual gravitavam praticamente todas as análises dos intelectuais ligados ao ISEB. A idéia da construção, da urgência, que já havia norteado outras gerações de intelectuais e políticos nas décadas de 1920, 1930 e 1940, encontra-se também nestes intelectuais desenvolvimentistas e nacionalistas, olhos fixos sobre a 'moderna cidade' que surgia (mesmo se não concordassem com o projeto) e mentes voltadas para o 'grandioso futuro da pátria'.

O caso do ISEB é, contudo, único no seu gênero. Não se pode considerá-lo simplesmente como um centro de pesquisas e é difícil considerá-lo uma "escola". Porém não se pode dizer que o pensamento isebiano estava isolado ou imerso em um meio hostil. Além de ter ouvido e comemorado o primeiro campeonato mundial de futebol em Brasília, numa estratégia de grande impacto sobre a opinião pública nacional, o governo $\mathrm{JK}$ convidaria, para visitar o canteiro de obras, personalidades como, por exemplo, Tom Jobim e Vinícius de Moraes, retirando dessa estratégia de pura propaganda, apoio e imagens (fotografias e filmes) dos mais diversos expoentes da vida nacional. A futura capital em construção numa região isolada demonstrava o arroubo do governo, reforçava a imagem mítica do começo e contribuiu em muito para o clima de ufanismo, de confiança no futuro naqueles ditos anos dourados.

Tentamos mostrar um sentido sutil que permitiu aproximar alguns daqueles que pensaram o Brasil durante os anos JK. Não se vislumbra, contudo uma relação de causa e efeito entre intelectuais do ISEB e o governo JK ou ainda entre os intelectuais e Brasília; tampouco há primazia em relação ao apoio ao projeto de transferência. Ao contrário, talvez se possa dizer que o elemento de ligação seja o sentimento da inexistência da nação. Eis o que nos remete à narrativa mítica de construção da nação: o desejo de construir a nação se manifesta apenas quando a engrenagem do pensar a questão nacional é posta em funcionamento. Trata-se assim de um mito que se manifesta quando, às condições sociais 
e intelectuais, soma-se o desejo de compreensão e, por vezes, a falta de dados e conhecimento para fazê-lo. Nestes momentos sim, considera-se que a nação está por se fazer; que há urgência etc. $\mathrm{O}$ poder de mito "modulador" é sempre atualizado em relação a cada contexto social e político.

$\mathrm{O}$ relacionamento de $\mathrm{JK}$ com o Instituto - as evidências indicam isso - , teve por base a semelhança nas análises sobre a realidade nacional, cujo pano de fundo foi o desenvolvimento. Não obstante, o tema do nacionalismo foi bem mais retórico do que propriamente econômico ou político para o governo $\mathrm{JK}$, do que o foi para intelectuais como Guerreiro Ramos, por exemplo. A relação de $\mathrm{JK}$ com os intelectuais ligados ao ISEB ganhou contornos especiais, talvez, devido aos laços de amizade que uniam JK a Roland Corbisier. Foi, de fato, este último quem mais abertamente apoiou a "ideologia nacional-desenvolvimentista" e também a construção de Brasília. Não obstante, outros intelectuais (Gilberto Freyre, por exemplo) mostraram-se favoráveis a Brasília, discutindo, contudo a sua urgência, o timming da construção e o processo de transferência das funções político-administrativas ou o sentido cultural da nova "brasilidade" anunciada. Em outra esfera, questões de relevo envolveram os debates acerca da nova capital: ora falou-se em industrialização e desenvolvimento, ora em segurança nacional e geopolítica. O desenvolvimentismo e/ou o nacional-desenvolvimentismo não apontavam necessariamente para a transferência da capital. Não há, portanto, relação de causalidade ou de determinância entre as principais teses do ISEB e a política do governo JK em relação a Brasília. Correspondências míticas talvez dêem conta melhor da realidade que fez unir alguns desses atores em torno do tema central que era a construção da nação, seja transferindo a capital, seja se opondo a ela. Nesse caso, a semelhança nas análises surge mais como fruto de substratos culturais míticos do que propriamente da lógica estrita das análises políticas ou intelectuais. 


\section{Notas}

1 Eram temas debatidos pelo Instituto Brasileiro de Economia, Sociologia e Política (IBESP) e publicados em sua revista "Cadernos do Nosso Tempo", entre 1953 e 1956.

2 Hoje o banco chama-se BNDES, acrescentando o "s" de social.

3 Esta denominação tem sua origem no local - Parque Nacional de Itatiaia - onde a partir de 1952 passou a se reunir o referido grupo. Deste fizeram parte Guerreiro Ramos, Ewaldo Corrêa Lima, Hélio Jaguaribe, Ignácio Rangel, para citar apenas aqueles mais conhecidos.

4 A CAPES foi criada em 1951, pelo Decreto Federal no 29.741. Sua criação insere-se no seio do projeto de "nação desenvolvida" formulado nos primeiros anos do governo Vargas.

5 Esta imagem deve-se, sobretudo ao período 1958-1960 curiosamente quando "sua" ideologia se afastava daquela de JK, em particular no que dizia respeito à soberania nacional e às transformações estruturais da sociedade.

6 Em um acerto cordial, Nélson W. Sodré (1978, p. 17) teria ficado com a parte de "história do Brasil" enquanto Cândido Mendes teria ficado com a "história geral".

7 A cadeira de Sociologia foi ocupada por Júlio Barbosa, em substituição a Guerreiro Ramos; a de Economia, por Ezio Távora dos Santos, em substituição a Ewaldo Correia; e a de História, apenas por Werneck Sodré com a passagem de Cândido Mendes para a de Política, que ficou vaga com o afastamento de Jaguaribe. Esta formação teria permanecido até 1964, quando do fechamento do Instituto.

8 De desigualdade, dizemos hoje.

9 Filósofo, ensaísta, articulista (Jornal do Brasil) e político, Corbisier foi diretor do ISEB, deputado federal e professor de Filosofia. Além dos livros citados, sua obra é grande e importante, com forte inclinação para a área de filosofia política. Uma análise desta e mesmo do personagem ultrapassaria em muito o escopo deste trabalho.

10 As outras conferências desse seminário não publicadas foram: "Significação geopolítica de Brasília", de Josué de Castro; "Brasília, 
marco histórico da criação de uma cultura mediterrânea", de Primo Nunes de Andrade; “Aspectos sociológicos e econômicos da mudança da capital", de Júlio Barbosa; "Aspectos institucionais da mudança da capital”, de José Joffily; e, “Arquitetura e urbanismo de Brasília”, de Augusto Guimarães Filho.

11 A idéia do mito ou da narrativa mítica enquanto elemento "modulador" da trajetória histórica é umas das principais teses defendidas pelo filósofo francês Gilbert Durand (1979, p. 31), que afirma: “... é o mito que 'faz' o momento histórico, a alma de uma época, de um século, de uma idade da vida. O mito é o módulo da história, não o inverso".

12 Curiosamente, este é o título de uma tese defendida no ISEB em 1958 (e publicada em maio de 1960, após a inauguração de Brasília) por Henrique L. C. de Castro. O essencial da tese de Castro é retomado na obra de Corbisier. Contudo, o trabalho de Castro é mais completo, com referências históricas à mudança, dados sobre o crescimento econômico do país, sobre o processo de interiorização provocado pela mudança e uma análise sobre o perfil integrador das rodovias que estavam sendo contruídas pelo governo JK e um balanço do estado da construção da cidade naquele ano de 1958.

13 A imagem da integração foi apresentada, desde o início das obras de construção, através de um cartão postal que mostrava as distâncias de todas as regiões do Brasil até Brasília.

14 Durante o período como diretor do ISEB (1955-1959), Corbisier, chefiando um grupo de alunos do instituto, visitou as obras de construção da capital.

15 No caso de Alberto Guerreiro Ramos é claro que a tese da "aplicação do conhecimento" não nascera ali. Sua mais forte expressão talvez esteja em $A$ redução sociológica, de 1945.

The Higher Institute of Brazilian Studies and the city of Brasilia: mythical accomplicity

Abstract: This paper works on the connection between the Higher Institute of Brazilian Studies (Instituto Superior de Estudos Brasileiros, ISEB) and the new capital of Brazil, the city of Brasília. We analyse the history of the Institute as well as the works of his 
professors Alberto Guerreiro Ramos, Hélio Jaguaribe and, above all, the works of Roland Corbisier (director of the Institute between 1955 and 1959). There are many points in common between the Institute and the nationalist ideologies. However, there is much more. By studying the history of the institute, the sociopolitical circunstances of this period and the policy of JK's government, we conclude that there's no causal relation among all of these ideas. Actually, there are mutual correspondences and mythical accomplicity among all of these social actors around the general theme of nation's building.

Key-words: ISEB; Brasília's city; Brazil; developmental nationalist ideology.

\section{Referências bibliográficas}

BANCO NACIONAL DE DESENVOLVIMENTO ECONÔMICO (BNDE). Quarta exposição sobre o Programa de Reaparelhamento Econômico. Rio de Janeiro, 1955.

BARIANI, Edson. ISEB: fábrica de controvérsias. Revista Espaço Acadêmico, n. 45, fev./2005. Disponível em: <www. espacoacademico. com.br>.

BOJUNGA, Cláudio. JK: o artista do impossivel. Rio de Janeiro: Objetiva, 2001.

CARDOSO, Míriam L. Ideologia do desenvolvimento: Brasil: JK-JQ. Rio de Janeiro: Paz e Terra, 1978.

CASTRO, Gileno. Brasília e a grande crise. Rio de Janeiro: Pongetti, 1961.

CASTRO, Henrique L. C. Brasília e o desenvolvimento nacional. Rio de Janeiro: DASP, 1960.

CORBISIER, Roland. Brasilia e o desenvolvimento nacional. Rio de Janeiro: MEC/ISEB, 1960.

. Formação e problema da cultura brasileira. Rio de Janeiro: MEC/ISEB, 1958.

. JK e a luta pela presidência: uma campanha civilista. Rio de Janeiro: Duas Cidades, 1976. 
CORBISIER, Roland. Responsabilidade das elites. São Paulo: Livraria Martins Editora, 1956.

DURAND, Gilbert. Figures mythiques et visage de l'oeuvre. Paris: Berg International, 1979.

FARO, C.; SILVA, Salomão L. Q. da. A década de 1950 e o Programa de Metas. In: GOMES, Ângela de C. O Brasil de JK. 2. ed. Rio de Janeiro: FGV Editora, 2002. p. 67-105.

FRANCO, Maria S. C. O tempo das ilusões. In: CHAUÍ, M.; FRANCO, M. S. C. Ideologia e mobilização popular. Rio de Janeiro: Paz e Terra, CEDEC, 1978. p. 151-209.

JAGUARIBE, Hélio. A Filosofia no Brasil. Rio de Janeiro: MEC/ISEB, 1957.

O nacionalismo na atualidade brasileira. Rio de Janeiro: MEC/ ISEB, 1958.

Jaguaribe revê a história, fala do presente e projeta o futuro [Entrevista concedida a Álvaro Kassab]. Jornal da UNICAMP, Campinas, p. 1, 6-7, 21-27 jun, 2004.

JOBIM, Danton. Brasília, centro da civilização mediterrânea. Revista Brasília, Rio de Janeiro, n. 9, p. 1, set. 1957.

LAFER, Celso. Os anos JK: seu impacto e significado. In: SAUDADES do Brasil: a era JK. Rio de Janeiro: CPDOC/FGV, Museu de Arte Moderna do Rio de Janeiro, Prefeitura da cidade do Rio de Janeiro, 1992. p. 11-15

LAMOUNIER, B. O ISEB: notas à margem de um debate. Discurso, São Paulo, n. 9, p.153-158, nov. 1978.

MICELI, Sérgio. Les intellectuels et le pouvoir au Brésil (1920-1945). Grenoble: PUG/MSH, 1981.

MORAES, Reginaldo. Celso Furtado: a fantasia organizada. Rio de Janeiro: Paz e Terra, 1985.

MOREIRA, Vânia M. L. Brasília: a construção da nacionalidade, um meio para muitos fins (1956-61). Vitória: EdUFES, 1998.

MOTA, Carlos G. Ideologia da cultura brasileira. 5. ed. São Paulo: Ática, 1985. 
OLIVEIRA, Márcio de. Brasília: o mito na trajetória da nação. Brasília: Paralelo 15, 2005.

.Étude sur l'imaginaire brésilien: le mythe de la nation et la ville de Brasília. Tese (Doutorado) - Universidade de Paris V, 1993. . Pensamento social brasileiro em perspectiva: três a(u)tores em cena. Comunicação \& Política, Rio de Janeiro, v. 4, n. 3, p. 129140, nova série, set./dez. 1997.

. Une mise en perspective historique du Mythe de la nation. Cahiers du Brésil Contemporain, MSH, Paris, n. 23/24, p. 129-143, 1994.

ORTIZ, Renato. Cultura brasileira \& Identidade nacional. São Paulo: Brasiliense, 1985.

PÉCAUT, Daniel. Os intelectuais e a política no Brasil. São Paulo: Editora Brasiliense, 1990.

PREBISCH, Raúl. O desenvolvimento econômico da América Latina e seus principais problemas. Revista Brasileira de Economia, Rio de Janeiro, v. 3, n. 3, set., 1949.

RAMOS, Alberto Guerreiro. O problema nacional do Brasil. Rio de Janeiro: Saga, 1960. . A redução sociológica. Rio de Janeiro: MEC/ISEB, 1958.

SCHWARTZMAN, Simon. O pensamento nacionalista e os Cadernos do Nosso Tempo. Brasília: Ed. da UnB, Câmara dos Deputados, 1981. (Biblioteca do Pensamento Político Brasileiro, v. 6).

SODRÉ, Nélson W. História do ISEB [parte 1]: Formação. Temas de Ciências Humanas, São Paulo, n. 1, p. 101-119, 1977.

. História do ISEB [parte 2]: Crise. Temas de Ciências Humanas, São Paulo, n. 2, p. 119-143, 1977. . A verdade sobre o ISEB. Rio de Janeiro: Avenir, 1978.

TOLEDO, Caio N. ISEB: fábrica de ideologia. São Paulo: Ática, 1978. 
TOLEDO, Caio N. Teoria e ideologia na perspectiva do ISEB. In: ANTUNES, R.; FERRANTE, V. B.; MORAES, R. (Orgs.). Inteligência brasileira. São Paulo: Brasiliense, 1986. p. 224-256.

TRINDADE, Cônego. Determinismo histórico da mudança da capital. Revista Brasília, Rio de Janeiro, n 19, p. 1, jun. 1958.

WERNECK, Humberto. O destino da rapaziada. In: BOJUNGA, Cláudio. JK: o artista do impossível. Rio de Janeiro: Objetiva, 2001. p. 156. 